\title{
The Impact of the Intellectual Capital of the University Administration in Achieving the Quality of Education
}

\author{
Saqer Sulimas Al-Tahat ${ }^{1}$, Alaa Jaber Matarneh ${ }^{2}$ \& Osama Abdul Moneim $\mathrm{Ali}^{2}$ \\ ${ }^{1}$ Faculty of Economics and Administrative Sciences, Al al-Bayt University, Al-Mafraq, Jordan \\ ${ }^{2}$ Faculty of Economics and Administrative Sciences, Jerash University, Jerash, Jordan \\ Correspondence: Saqer Sulimas Al-Tahat, Faculty of Economics and Administrative Sciences, Al al-Bayt \\ University, P.O. BOX 130040, Mafraq 25113, Jordan. Tel: 962-776-778-091. E-mail: saltahat@ yahoo.com
}

Received: November 13, 2018

Accepted: January 13, 2019

Online Published: January 17, 2019

doi:10.5539/ijef.v11n2p137

URL: https://doi.org/10.5539/ijef.v11n2p137

\begin{abstract}
The rational and entrepreneurial universities are working in the possession of an important resource, which is the intellectual capital, to reach the local and global leadership, Such study aims at stating the intellectual capital impact of the rational university administration in accomplishing its quality of education since the study population consisted of both public and private Jordanian University while the study sample reached to (45) faculty members were chosen randomly and were working in such Universities, a questionnaire has been designed and distributed on (45) faculty members of the study population, who were working in such Universities, for the purpose of achieving the study aims as well as the essential statistical exams have been conducted whereas the findings showed that there is an impact of the intellectual capital) for the rational University administration of the different kinds of the Universities (the humankind, the structural, and the relational in achieving its quality of education while the study recommendations revolve around the necessity of the Universities in identifying the intellectual capital and determining the practical means to preserve and improve it in order to guarantee its quality of education.
\end{abstract}

Keywords: the intellectual capital, the quality of education

\section{The Introduction}

The justifications of concerning in the intellectual capital emerged from the trailblazing Universities that are eager to the global competition since it plays an important and vital role in improving the creative abilities for its faculty members, such thing led the rational administration of the University concerning in the strategic plans for attracting such importance resource for improving its educational deficiency, the importance of the intellectual capital in the Universities manifests in the importance of its components in general and of the human capital for its faculty members in particular. The human component in the University considered as a basic building block of the University and without it the University will not be able to exist, the importance of such human component of the University emerges from the knowledge, the skills, the intellectual and mental abilities of the faculty members which the University administration can take advantages of them in improving the activities and the processes that achieves its creativity and excellence, the successful faculty members undoubtedly contribute in achieving the trailblazing for the educational institution in addition to its contribution in developing the regulations and the intellectual techniques that are related to any University such thing indicates the human brain components of the faculty member plays a role in achieving the competitiveness to the Universities, which will help the Universities to improve their efficiency and educational capacity, Leading to an improvement in its global and local market value. Thus, the rational administration in the Universities shall pay attention to such essential intellectual resource; such study aims at stating the rational administration impact in the Universities in developing the intellectual capital of teaching it in order to reach to its quality of education.

\subsection{Purposes of the Study}

Such study aims at knowing the trailblazing impact of the intellectual capital components (human, structural, relational) and the quality of education for both public and private Jordanian Universities to improve its educational quality at the local and global levels. 


\subsection{The Significance of the Study}

The significance of the study arises from the value of intellectual capital since it's considered as an important resource for superiority to any educational institution and the main supporter for the competitiveness among them. In fact, the Universities attention to such intellectual capital imposed by the extent of scientific and economic challenges, the rapid technological developments, the extreme competitiveness pressure surrounding the Universities in all over the world. The creative intellectual abilities of the faculty members became one of the most excellence factors to any University in the shadow of the global economy that based on knowledge, each creativity and invention began with an ingenious idea.

The process of establishing the intellectual base constitutes a big challenge for the supreme administrations in various universities, it requires exerting a lot of efforts, time, and money, such thing may go beyond leading such administration to reorganization and engineering of new activities and processes to increase its intellectual and creative capacities. Thus, the importance of human capital investment emerges and considered one of the intellectual capital types.

\subsection{The Problem of the Study}

The intangible assets constitute a big portion of the capital for various educational institutions in the current time, the educational institutions concerned in measuring their performance by their tangible assets, since the quality of education competence has been measured by the accredited profit on the tangible assets only, because of the changing in the business environment related to the educational institution. A huge transformation emerged in the notion of quality measuring since it has been taken into consideration what Universities have of intangible assets that represented in the intellectual capital because it has trailblazing impact on improving its quality of education.

Thus the problem of the study revolves around the following questions:

\subsubsection{The Main Problem}

Is there any impact that has statistical indication to the intellectual capital to the rational administration in achieving its quality of education?

\subsubsection{The Following Sub-Questions Branching Off from the Main Question}

The first sub-question: is there an impact that has a statistical indication on the human capital to the rational administration in achieving its quality of education?

The second sub-question: is there an impact that has a statistical indication on the structural capital to the rational administration in achieving its quality of education?

The third sub-question: is there an impact that has a statistical indication on the relational capital to the rational administration in achieving its quality of education?

\subsection{The Hypothesis of the Study}

On the basis of the questions of the problem, the study hypotheses revolve around the following things:

\section{HO The Main hypothesis}

There is no statistical impact on the intellectual capital to the rational administration in achieving its quality of education.

\section{The following sub-hypotheses branching off from the main hypothesis}

H01: There is no statistical impact on the human capital to the rational administration in achieving its quality of education.

H02: There is no statistical impact on the structural capital to the rational administration in achieving its quality of education.

HO3: There is no statistical impact on the relational capital to the rational administration in achieving its quality of education.

\subsection{Previous Studies}

Study of (Cricelli et al., 2018) by the title of "Intellectual capital and university performance in emerging countries Evidence from Colombian public universities".

Such study aims at exploring the relation between the intellectual capital and the performance of the public Universities in the emerging countries for the purpose of identifying the patterns and providing the 
recommendations that may transform the intellectual capital of the universities to the opportunities in terms of researching, innovating, and learning. The study resorted to make indeterminate analyzing to the public Universities in the Republic of Colombia. The results of the study showed that the aspects of the intellectual capital are correlated with the Universities' performance. The study suggested an innovative model in order to analyze the relation between the intellectual capital and the University's performance in the emerging countries.

Study of (Alserhan, 2017) by the title of "The Role of Intellectual Capital in Achieving the competitive Advantage: A field study on Jordanian Private Universities in the Northern Region".

Such study aims at identifying the intellectual capital roles and its components (the human capital, the relational capital, the structural capital) in achieving the competitiveness feature and its dimensions (the quality, the competence, the innovation and the responsiveness) in the private Jordanian Universities in the Northern territory. A questionnaire has been designed and distributed on a sample consists of 90 person of the studying community out of 120. Such study has concluded to the existence of a relation that has a statistical indication among the intellectual capital and its three dimensions and achieving the competitiveness feature, the study also shows that the human and relational capital dimensions are more competitive than structural capital .

Study of (Rezende et al., 2017) by the title of "The Intellectual Capital and Value Creation on the Brazilian Higher Education Institutions: Perspectives of the Coordinators of Undergraduate Business Administration Courses".

Such study sheds the light on the role of the intellectual capital and its dimensions in creating the value for the stakeholders in the Brazilian Higher Education Institutions on the basis of the coordinators of the University business administration programs in Rio de Janeiro in Brazil. The methodology of the research based on the semi-organized interviews, Questions have been raised on the participants about the dimensions of the intellectual capital administration and the effects that are resulted from depending on the multi-dimensional balanced score card, such study has come up with the existence of influential evidences related to the adoption of the social shares system, the dual nature of the relational capital, improving the stakeholders' results when adopting the balanced score card.

Study of (Alawamrah, 2016), under the title of "Influential Relationship between Intellectual Capital and the Development of Creative Abilities of the Faculty Members in The Faculty of Educational Sciences- University of Jordan".

Such study aims at measuring the effect of the intellectual capital dimensions on the creative abilities of the faculty members in the Faculty of Education- Jordanian University. A questionnaire composed of 27 paragraph has been prepared and distributed on the faculty members in the faculty of educational sciences. This study has come up with the existence of the statistical indication impact among the intellectual capital and creative abilities of the faculty members. Also it showed that statistical indication differences were existed in the sample of study trends towards both the intellectual capital due to the variations of the years of experience in the University and to the creative abilities due to the variations of the academic rank as well as years of experience.

Study of (Barbosa et al., 2016) by the title of Intellectual Capital and Performance in Higher Education Organizations.

Such exploratory study aimed at clarifying the proportional importance to the dimensions of the different intellectual capital dimensions in respect to its contribution in the conceivable performance to the Portuguese Higher Education Organization (HEO), it strives also in discussing the role of intellectual capital and measuring the organizations' performance. The study indicated that all the human, structural, and relational capitals have to contribute in the performance of the Portuguese Higher Education Organization. However, the human resources has an additional importance as a knowledge resource in addition to the existence of overlapping between the intellectual capital dimensions and the performance indicators.

Study of (Al Garaawi \& Hamood, 2016) entitled by: The extent of the application of the principles of total quality management in higher education: a comparative study between the government colleges and community colleges from the viewpoint of a sample of lecturers.

The study is interested in determining the extent of applying the principles of the comprehensive quality administration in the higher education sector and knowing the extent of applying such principles between the governmental and national faculties by comparing among them, the study adopted the analytical descriptive methodology in identifying and treating its dynamics. In addition, prepared multi measures have been adopted and developed in line with the study purposes and the nature of the environment that has been examined.

the main hypotheses that led to emerging sub-hypotheses were formulated, For the purpose of achieving the 
study objectives, they have been tested on a sample consisted of 200 member of the faculty by the ratio of 115 member of the governmental faculties and 85 member of the national facilities, the researcher adopted the questionnaire in the entire essential data of the research, and for verifying the acceptance of the study hypotheses a number of statistical means have been used, the most prominent means are: the arithmetic mean, the standard deviation, the centric weight, the relative importance, Wilks Lambda test, Chi-square test, Discernment analysis test.

The most prominent findings that have been reached in such study are the comprehensive awareness and realization of teachers by mentioning the importance of the comprehensive quality administration and its principles, but there are variations. On the first hand, in applying such principles in the governmental sector. On the other hand, because of the huge variation with the national sector. Thus, the researcher recommends that the governmental faculties may attract and maintain the members of the scientific degrees as long as possible by imposing some of the regulations whether by contracting with their elderly or by remunerative paying equally with national faculties.

Study (Alzoubaidi et al., 2017) by the title of :analyzing the dimensions of the intellectual capital in the educational institution by using SWOT technique.

The purpose of such study is knowing the role of using SWOT device in analyzing the intellectual capital in the educational organizations. The intellectual capital considered as a primary dynamic to the activates and all tasks that such organizations perform. Such organizations resemble the building block in establishing and developing any country in the world. It considers essential to take advantage of the modern devices in analyzing its intellectual capital. The most prominent devices is SWOT device since it focuses on determining the internal strengths and weakness points in addition to the opportunities and the external threats that impede the improving of the intellectual capital, a questionnaire has been adopted as a tool for obtaining the research data. "Algharbiah" middle school for boys has been used as a field of research. The sample of the study has been chosen randomly from the two universal teachings in such school and its size has reached to 43 member, Statistical Package for the Social Sciences program (SPSS) has been used in entering and analysing the study data. The data findings have confirmed that a correlation and influence relation of a moral significance among using SWOT device and analyzing the intellectual capital in the educational organizations. Thus, the researchers recommended the need for increased attention in studying the most important devices and modern techniques of high competence in analyzing the intellectual capital in a way that assist it in determining the most important strengths and weaknesses points of its intellectual capital, in addition to determining the opportunities and threats that impedes its developing process.

\section{The Methodology of Study}

\subsection{Resources of the study}

The descriptive and analytical methods have been used in such study, the researchers got the essential data of such study from the following resources:

- Primary Resources

- Secondary Resources

Primary Resources:

The essential primary data of such study has been obtained through a questionnaire that has been prepared and distributed on the prominent intellectual qualified faculty members in the Jordanian Universities, such data constituted the sample of the study. Then the data was gathered and analysed by using the Statistical Package for the Social Sciences (SPSS) in order to test the validity of the study hypotheses.

\section{Secondary Resources:}

The secondary data related to such study has been obtained by referring to books, university thesis, the scientific researches, reports, the articles in newspapers and magazines for the purpose of establishing the theoretical framework of the study and to achieving its goals.

\subsection{The Study Community}

The study community composes of both public and private Jordanian Universities.

\subsection{The Study Sample}

Since the study community is from public and private Jordanian Universities. Thus, a sample composes of (45) member of the faculty members will be chosen randomly. 


\subsection{Theoretical Framework}

\subsubsection{The Concept and the Importance of the Intellectual Capital and its Characteristics}

The meaning of the creative intellectual conception to the intellectual capital terminology expresses that there are denotations exist with such pioneering concept it emerges in two creative terminologies, such as thinking and knowledge.

(Alzyadat, 2015) states that thinking is a noun derives from think which means: the brain's missions in the known things in order to reach to the unknown things. It has been said: I have a thought in an issue: it means perspective and vision. I don't think about something: it means I don't think and I don't care while the knowledge has been identified as: he/she realized it by one of his/her senses then he/she has known a thing.

(Hussein, 2010, p. 138) identifies the intellectual capital as everything emerges in the human whether the knowledge, skills, and abilities that contributes in achieving the competitive feature to the Universities.

(Al Hussaine, 2009) also identifies such definition as: the features and the impeded characteristics that are existed in a group of staff working in the Universities, organizations, the people who have mental and intellectual capabilities that are represented in knowledge, skills, the essential experiences either to create innovation or to product new ideas or to develop such old ideas all the aforementioned things lead the Universities and organizations achieve profits, increase their market value, and optimize their competitive center compared to other organizations or Universities:

(Omar \& Hamdi, 2011) suggest that: mental and intellectual thoughts that specific group of staff working especially the faculty members of the community have them, such thoughts contribute in achieving progress and development in the functions, activities, and processes that are carried out by the Universities in order to provide ideas as well as new suggestions and to renew the old suggestions such thing lead the university to achieve the sustainable competitive feature comparing to other local and global Universities.

The importance of the intellectual capital emerges from the organizational, vocational, behavioral, and personal features that the capital have, the intellectual capital features are represented in the following things:

1) The intellectual capital is characterized by decentralization and it avoids the centralization in the administrative work. Consequently, it enables it's members to take advantage of their competences, skills in achieving the creativity and innovation such thing contributes in developing, improving, and achieving the goals of the organizations and Universities.

2) The intellectual capital exists in all the organizational levels in the Universities.

3) The intellectual capital interacts with the flexible organizational chart for both University and the organization.

4) The intellectual capital composes of knowledge, skills, experiences, its completely known that such components generated through the sustainable work, education, and training and confronting the working problems. Consequently, concentrating on the educational level shall not be considered as a vital component of the intellectual capital instead it shall be considered as a supportive and complimentary for such components.

5) Considering that the intellectual and mental abilities of the human mind are the basis of intellectual capital, intellectual capital has a relatively high level of intelligence, and seeks to initiate the presentation of ideas and constructive proposals and dealing with situations that bear the risk and uncertainty

6) The intellectual capital characterizes by perseverance and independency in working. Moreover, it also has high self-esteem.

7) The intellectual capital characterizes by the ability of speculating and issuing conclusive decisions

2.4.2 The Importance of the Interaction of the Intellectual Capital Components of the University and Its Intellectual Characteristics

(Alserhan, 2017) states that the intellectual capital became the main component and the important resource in innovation, changing, and creativity processes. Consequently, it creates competitive feature to the organization and educational institutions equally. Accordingly, whenever the organization and the educational institutions were able to evaluate in appropriate way its intellectual capital, it will be able to achieve its goals and take decisions that are related to redesign their programs. Leading such institutions to become more competence, profit, and competitive with regard to the product quality, educational service, cost, price, and any other excellence strategies. 
(Al-Hawary \& Nusair, 2017) declare that the competitiveness level has increased sharply recently. Since the University's effectiveness closely correlated with its potencies to compete, continue, and to remain by developing its leader's and employee's ability represented in the rational administration which constitutes its intellectual capital. In addition, the minority of its internal and external relations and systems regarding to its educational surrounding.

(Al-Hawary \& Nusair, 2017) state that for many years the material assets indicators were the main indicator for measuring the performance of the organizations and the successful educational institution, but in 1980 the situation has changed especially after the information technology revolution, since the organizations and educational institutions were not only confined to the material assets but also to the intellectual capital for such people who lead its rational administration,

(Ognjanović, 2016) says that in the contemporary circumstances creating the economical value is based upon knowledge, and other non-material resources, whereas the knowledge considered as a main resource for the modern economic and the workers in the knowledge domain shall be considered the most important labour force.

(Dahlman, 2002) indicates that various things have to be obtained in order to create a society that based upon knowledge, such as improving knowledges, developing technology, enhancing relations between the economical processes and practical bases, increasing the ratio of innovation and the productive courses, increasing the concentration on knowledge, intellectual capital, and the sustainable education, increasing the investments in intangible assets comparing to tangible assets, public relations as well as marketing, and information management.

(Ricceri, 2008) the intellectual capital in the Universities composes of the following things:

- Human capital indicates to all explicit and implicit knowledges and skills, the teaching personnel, researchers, managers, employees and students.

- The structural capital indicates to the knowledge that is embedded in the organization's structure, the governance systems, routine as well as procedures and organizational culture.

- The relational capital indicates to the knowledge flows that considered as a building block between the University and its environment.

- (Alawamrah, 2016) mentions the most important characteristics of the intellectual capitals in the Universities:

- The organizational characteristics.

- The vocational characteristics.

- The personal and behavioral characteristics (the human component).

The researchers think that the interaction between the components of the intellectual capital in the Universities will undoubtedly help in determining the value of the Universities' overall intellectual capital. In other words, the Universities whose members have leadership teaching they actually have such important resource in addition to competences, skills, innovations, creativity, and the ability to learn. Moreover, such University has effective organizational structures, data base, polices and clear procedures, a developed information technology system, in such case it will largely contribute in achieving its educational goals whether in local or global levels.

\subsubsection{The Importance of Measuring the Intellectual Capital Value in the Universities}

(Marr \& Neely, 2003) and (Kannan \& Aulbur, 2004) think that the importance of intellectual capital in the Universities manifests in two main levels:

1) The importance of measuring the intellectual capital at the internal level:

- Formulating University's strategies.

- The contribution in evaluating the implementation of the University's strategy.

○ The contribution in developing the systems of leader's awards in the Universities.

2) At the external level (stakeholders):

- Providing information about the future performance of the University that investors, lenders, and concerned persons may use.

- Reducing the problem of the available information asymmetry among the beneficiaries. 
- Encouraging the educational institutions and supporting its capacities in order to affect the shares price of the educational institutions.

(Todericiu \& Stanit, 2016) state that the importance of analysing the intellectual knowledge in the universities in the shadow of the knowledge economy: although knowledge analysing and the intellectual capital have been related to the companies recently, but today we witness an increasing interest in determining and evaluating the intellectual capital for the universities. Each University has its own intellectual capital that is used to attract students, experts, and the future co-operators.

(Ramírez, Tejada, \& Gordillo, 2013) mention that there is an increasing interest in applying the intellectual capital approach in the Universities, producing and distributing knowledge (research fields \& human resources) considered amongst the main aims of the Universities. Consequently, the higher education institutions considered as an ideal framework for applying the ideas that are related to the intellectual capital theory.

(Canibano \& Sanchez, 2008) state that the stakeholders increasing demand for obtaining transparency and increasing the competitiveness and independency amongst Universities and institutions, led the Universities to employ new reporting systems that include intangible assets. The Universities produce knowledge either by technical or practical researches (studies' and researches' results) or by teaching (the trained students, the productive relationships with stakeholders); the most valuable university's resources are the teaching personnel, researchers, employees, and the heads of Universities. The intellectual capital in the Universities generally point out to covering the intangible or non-material assets, such as innovations, patents, the implicit knowledge, capabilities, hobbies, and skills of its members.

(Rizvi, 2005) indicates that there are various reasons for analysing the intellectual capital in the Universities in the shadow of the knowledge economy, such as:

1) In the knowledge community, the citizens shall learn more about the general financing.

2) If the Universities want to acquire a lot of information about the intellectual capital, then the best transferred practices shall be improved.

3) Enhancing the relations among the business sector and Universities, such thing shall not be accomplished without having a common language.

4) The difficulty of concealing the weak results for some researchers because of determining and defining a clear group of indicators and evaluation methodology.

5) (Todericiu \& Stanit, 2016) states that the Universities considered as the main infrastructure component for knowledge and innovation especially in the community that relies on knowledge, Universities bear clear social responsibility based on its duties in minimizing the development's gaps by transferring knowledge and finding common solutions to enhance the labor force.

The relation between the intellectual capital and the systematic performance in the Universities and reaching to the global and local competitiveness:

(Hadad, 2017) indicates that the Universities play in the knowledge economy a crucial and a vital role for knowledge and a territorial motivator for the social and economical improvement. (Secundo et al., 2017) confirms that the knowledge that is produced from the Universities may motivate the innovation in the business field, and enhance the competitive capability and economical development. Thus, the Universities have to harmonize their policies with other interactive community bodies in order to facilitate at the regional level the technological and economical specialization. In the recent decades the investment structure has been clearly changed, in a manner that made the tangible assets the only investment kind, the investment in the intangible assets has been increased. For instance, in the United States of America in the period between 1972-2011 the tangible assets investments have been decreased from $12 \%$ to $8 \%$ while the intangible assets have been increased from $8 \%$ to $15 \%$.

(Ramona \& Anca, 2015) state that the relation among the intellectual capital and the structural performance is the main reason behind the University's concern of the intellectual capital evaluation. The Universities still confronting the evaluation problem in order to increase their competitiveness capabilities. In this regard, a series of reports has been recently established in order to resolve this problem by setting out a unified evaluation system, such as guiding principles for management and reporting on the intangible assets (the European Commission 2006), the intellectual capital report 1999-2004 (Austrian researches centres, 2005), the intellectual capital data- new trends (the Norwegian Ministry of Innovation, Technology, and Science 2003). (Ramona \& Anca, 2015). 
The intellectual capital indicators considered useful as a reference tool but there are certain things that have to be taken into consideration:

In order to compare between two Universities from the intellectual capital perspective, the differences in the data that are related to their tasks, strategies, dimensions, as well as their establishment source have to be evaluated.

(Ramona \& Anca, 2015) state that the comparison shall be related only when taken into consideration the time that just data gathering have been accomplished in order to develop the indictors also. The Universities either may be in different stages of their intellectual tactic, or may be their strategies have been sharply affected in certain stage by the external environmental factors.

The teaching staff and the University pedagogical in order to reach to the educational quality in the Islamic World Universities (Islamic Universities Union, 2010, pp. 47-48).

The leadership Universities that strive to reach to the educational quality have to establish in its policies the following things:

1) The faculty members shall carry out an outstanding mission in developing the University education. Therefore, the teachers were the main education pillar in the University because they produced and distributed knowledge by different means.

2) The number of University's teachers and counselors has been doubled due to the increasing development that has been noticed in the modern Universities in all over the Islamic countries and to the data variations and changes in the scientific and cultural trends because of the aforementioned reasons the teachers began to seeking for renewed positions, it became essential that the formative activities balance whether among the general theoretical education, vocational formative, and scientific research. The teacher's mission and his/ her functions have been varied due to the progressive increasing in vocation kinds and types of vocational data that various Islamic Universities have witnessed them. However, the teacher's mission was delivering the comprehensive primary knowledge now it has been extended to include rehabilitating the student for the purpose of social integration and vocational practice.

The teacher was not the only source for knowledge since the variations of other resources that compete him/her more and more which that manifest in various communication devices. Such resources have emerged in the University community gradually by the necessity of considering the effectiveness indicator in the teachers' education process that result in learning and achieving and students' satisfaction. Nevertheless, the teaching staff considered one of the most important inputs in the educational system and in each level of educational process as well as the most effective factor in the level of outputs quality. Accordingly, the teaching staff level and the circumstances that they initiate their job considered from the defined variables for their effectiveness and to the quality of the missions that are imposed on them whether teaching, supervising on the students' research and community service.

It shall be noticed through literature and researches that due to the general level of the faculty members in several of Islamic countries and the circumstances of their work the following problems are emerged:

1) The general conditions in the University and Higher education in various of Islamic countries are not encouraging, such as the low level appreciation whether to the science or scholars in some communities, the social and political poor levels, the lack of opportunities for academic and educational development.

2) A huge number of faculty members did not sufficiently use the tremendous development of information and communication technologies in their jobs in faculties and higher institutions, such things didn't motivate them to develop learning methods, types, and patterns.

The faculty members inputs for the purpose of reaching to the higher education quality:

There are various inputs for the vocational development to the faculty members, they can be briefly summarized the following things:

1) The conscious practice:

It can be clearly defined as thinking in the educational attitude and its various components before implementing it, as well as a prior planning for both such attitude and its implementation (reflexion on action) rethinking during implementation (reflexion in action) thinking after implementation in order to know the variations that may happen between objectives and the achieved objectives. The conscious practice is like a circle track that starts by notice and description of the educational learning status then analyzing the factors that are controlling such phenomenon, in order to reach to new findings and concepts, sitting out an experimental plan to improve and implement practice on the general findings and concepts rule (Figure 1): 


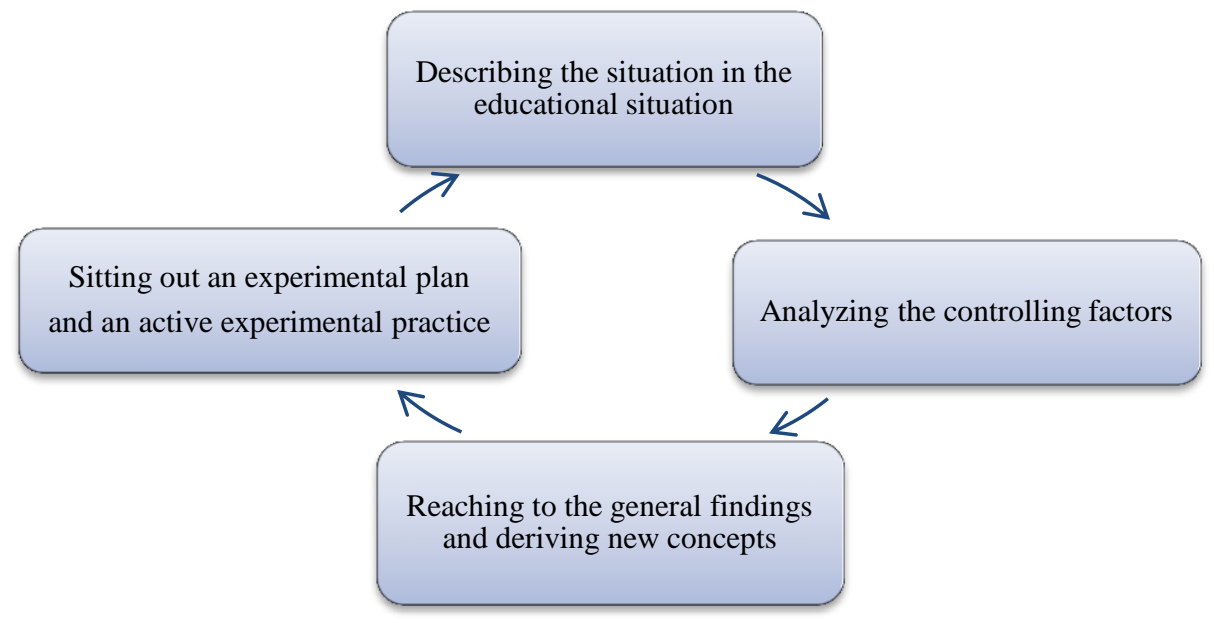

Figure 1. The conscious practice

2) The scientific or procedural research input:

The actual research particularly manifest during the last three decades of the twentieth century in England and United States of America by the method called improving the educational institution, then it has spread in various countries like France and Canada. It shall be represented when a teaching member inspect his teaching practice and decide to develop it and to develop his/her educational strategies, determining the problems that may arise, and the dimensions that are linked to such practice, evaluating his/her performance, choosing the most appropriate act, sitting out his decisions and putting them into effect in order to cause a change. In such case the actual or procedural research becomes as one of the vocational development inputs.

\section{The Practical Part of Studying}

\section{The Studying Tool Stability Test}

The internal alignment factors (Cronbach's Alpha) have been calculated, the results were as follows:

Table 1. The internal alignment factors for teaching tools paragraphs

\begin{tabular}{llc}
\hline No. & \multicolumn{1}{c}{ Dimension } & Alpha value \\
\hline 1 & The main capital (human resources management and the knowledge that such resources have. & 0.770 \\
2 & The structural capital (the infrastructure for the University and knowledge). & 0.865 \\
3 & The relational capital (clients' relations) & 0.703 \\
\hline All paragraphs & 0.915 \\
\hline
\end{tabular}

We noticed that internal alignment factors (Cronbach's Alpha) for the studying performance paragraph has ranged between (0.703-0.865), Alpha's value for all paragraphs was (0.915). consequently, all values shall be more than (0.60) such thing considered as an indicator to the harmonization between the studying tools paragraphs, the reliability of studying performance and the ability to depend on such tools in order to perform the statistical analysis.

\subsection{Data Analysis and Hypothesis Testing}

This chapter describes and analyzes the study data. It describes the characteristics of the study sample, a description of its variables, the relative importance of the study paragraphs, an analysis of the answers to the study questions, and the testing and commenting on hypotheses.

\subsubsection{Describing the Characteristics of the Study Sample}

Describing the characteristics of the study sample: such section includes a description to the definitional characteristics and demographic to the study sample members. The iterations and the percentages of the demographic variables of the study sample have been found in order to describe the characteristics of the study sample as follows:

1) Age: 
Table 2. The sample members according to the age variable

\begin{tabular}{cccc}
\hline Variable & Category & Iteration & Percentage \\
\hline \multirow{2}{*}{ Age } & Less than 30 & 6 & 13.3 \\
& $30-40$ & 30 & 66.6 \\
& More than 40 & 9 & 20.1 \\
\hline Total & & 45 & 100 \\
\hline
\end{tabular}

It has been clearly identified from the Table 2 that the age group (30-40) contributed the majority of the study sample member, such thing indicates the high level of interest shown by the faculty members in the Universities in stating the opinion.

\section{2) Gender:}

Table 3. The sample members according to the gender variable

\begin{tabular}{cccc}
\hline Variable & Category & Iteration & Percentage \\
\hline \multirow{2}{*}{ Gender } & Male & 40 & 88.9 \\
& Female & 5 & 11.1 \\
\hline Total & & 45 & 100 \\
\hline
\end{tabular}

It has been clearly stated from the Table 3 that males contribute $(88.9 \%)$ of the study sample while females contributed (11.1) of the sample because men precede women in entering the labor market. Consequently, they reach to the highest levels and centers in certain areas before women.

3) The educational level:

Table 4. The sample members according to the educational level variable

\begin{tabular}{llll}
\hline Variable & Category & Iteration & Percentage \\
\hline \multirow{3}{*}{ Educational level } & Doctoral & 35 & 77.8 \\
& Master & 10 & 22.2 \\
& Bachelor & 45 & 100 \\
\hline
\end{tabular}

It has been clearly noticed from the Table 4 that doctoral students have contributed the majority of the study sample and their percentage reached $(77.8 \%$ ), such thing denotes experience and scientific competence that faculty members in the Universities hold, it also consistent with the general trend to the higher education in the Universities provided that the faculty member in the University shall obtain at least a master degree.

4) Specialization

Table 5. The study sample according to the specialization variable

\begin{tabular}{llll}
\hline \multicolumn{1}{c}{ Variable } & \multicolumn{1}{c}{ Category } & Iteration & Percentage \\
\hline & Accounting & 30 & 66.6 \\
Specialization & Business Administration & 6 & 13.3 \\
& Banking and financial sciences & 6 & 13.3 \\
& Others & 3 & 6.8 \\
\hline Total & & 45 & 100 \\
\hline
\end{tabular}

Table 5 shows the diversity of the specialties of the study sample. The percentage of specialization in finance and administration (accounting, business administration, finance and banking) reached 93.2\%. While the percentage of other majors (Arts and Languages, Sharia, Law and Science) was $6.8 \%$.

5) Educational level 
Table 6 . The distribution of study sample according to the educational level variable

\begin{tabular}{clll}
\hline Variable & Category & Iteration & Percentage \\
\hline \multirow{3}{*}{ Educational level } & Assistant professor & 20 & 44.5 \\
& Teacher & 10 & 22.2 \\
& Associate professor & 12 & 26.7 \\
& Doctor teacher & 3 & 6.6 \\
\hline Total & & 45 & 100 \\
\hline
\end{tabular}

We can clearly notice from the Table 6 that "Assistant professor" category has contributed the largest category and its proportion reached to (44.5\%) such thing denotes the University's interest in the status and educational rank for the faculty members in the University and the university's motivation to such staff in order to enable them to reach to the highest ranks and scientific levels.

6) Years of Experience:

Table 7. The distribution of the sample members according to the years of experience variable

\begin{tabular}{lcll}
\hline Variable & Category & Iteration & Percentage \\
\hline \multirow{3}{*}{ Years of Experience } & Five years and less & 2 & 4.4 \\
& From 6-10 & 3 & 6.6 \\
& More than 10 years & 40 & 88.9 \\
\hline Total & & 45 & 100 \\
\hline
\end{tabular}

We can clearly notice from Table 7 that years of experience (more than 10 years has contributed the largest category and its proportion reached to (88.9\%) such thing indicates that the majority of sample members enjoy high experience

\subsubsection{Analyzing the Study Questions}

Such portion of the study presents a description of the study sample and questionnaire paragraphs, the arithmetical averages and the standard deviations for such paragraphs have been calculated, for the purpose of judging on the level of approval and identifying the relative importance for each paragraph, the results were as follows:

\subsubsection{The Human Capital (Managing the Human Resources and the Knowledge that Such Resources Have)}

Table 8. Arithmetic averages and standard deviations for the human capital paragraphs.

\begin{tabular}{|c|c|c|c|c|c|}
\hline No. & paragraph & $\begin{array}{c}\text { The arithmetic } \\
\text { average }\end{array}$ & $\begin{array}{l}\text { Standard } \\
\text { deviation }\end{array}$ & Rank & $\begin{array}{l}\text { Relative } \\
\text { Importance }\end{array}$ \\
\hline 1. & Management has clear knowledge of human capital concepts. & 4.222 & 0.647 & 3 & high \\
\hline 2. & The management has written trends to develop the human capital & 3.944 & 0.802 & 5 & high \\
\hline 3. & $\begin{array}{l}\text { The University has a written policy on the training and development of its } \\
\text { staff. }\end{array}$ & 4.000 & 0.840 & 4 & high \\
\hline 4. & $\begin{array}{l}\text { The turnover rate is minimal compared to other universities operating in the } \\
\text { same field. }\end{array}$ & 3.833 & 0.618 & 6 & high \\
\hline 5. & $\begin{array}{l}\text { Management is concerned with the outstanding employee and reward him } \\
\text { with the Employee Excellence Certificate (Ideal). }\end{array}$ & 3.278 & 0.958 & 10 & medium \\
\hline 6. & $\begin{array}{l}\text { The University measures the degree of improvement in the performance of } \\
\text { its staff and their contribution to decision-making. }\end{array}$ & 3.778 & 0.943 & 7 & high \\
\hline 7. & $\begin{array}{l}\text { Employees have the ability to cope with critical work situations and the } \\
\text { ability to deal with them in favor of work. }\end{array}$ & 4.222 & 0.732 & 3 & high \\
\hline 8. & $\begin{array}{l}\text { Senior Assistants have the skills, knowledge and leadership ability to take } \\
\text { top leadership positions at the University. }\end{array}$ & 4.389 & 0.608 & 1 & high \\
\hline 9. & The University documents all work procedures within written policies. & 4.278 & 0.575 & 2 & high \\
\hline 10. & $\begin{array}{l}\text { Senior management assistants are allowed to take leadership roles in senior } \\
\text { management during senior management leave. }\end{array}$ & 4.278 & 0.752 & 2 & high \\
\hline 11. & There are induction programs for new employees at the university. & 3.167 & 1.043 & 11 & medium \\
\hline 12. & The reasons for resignation of staff are discussed. & 3.389 & 1.037 & 9 & medium \\
\hline 13 & The University has a measure of the continuous learning capacity of its staff. & 3.500 & 1.043 & 8 & medium \\
\hline \multicolumn{2}{|c|}{ General Measure } & 3.868 & 0.429 & & high \\
\hline
\end{tabular}


From the above table, the relative importance of the general average of human capital (human resource management and knowledge resources) is high, with a general average (3.868) and a standard deviation (0.429). The paragraph "Senior Assistants for Senior Management has the skills, knowledge and leadership ability to qualify for senior leadership positions at the university" ranked first with an average of 4.389 and a high relative importance, while the paragraph "There are programs for induction of new employees at the university" ranked last, (3.167), with a relative importance

\subsubsection{Structural Capital (University Infrastructure and Knowledge)}

Table 9. Arithmetical averages and standard deviations of structural capital clauses

\begin{tabular}{|c|c|c|c|c|c|}
\hline No. & paragraph & $\begin{array}{c}\text { The arithmetic } \\
\text { average }\end{array}$ & $\begin{array}{l}\text { Standard } \\
\text { deviation }\end{array}$ & Rank & $\begin{array}{c}\text { Relative } \\
\text { Importance }\end{array}$ \\
\hline 1. & $\begin{array}{l}\text { The management has a complete knowledge about the structural capital } \\
\text { (the infrastructure and knowledge). }\end{array}$ & 4.333 & 0.594 & 3 & high \\
\hline 2. & The higher education has written trends to develop the structural capital & 3.889 & 0.832 & 6 & high \\
\hline 3. & $\begin{array}{l}\text { There is a continuous improvement to the infrastructure of the } \\
\text { University (equipment and devices, building abilities and technologies) }\end{array}$ & 4.000 & 0.970 & 4 & high \\
\hline 4. & $\begin{array}{l}\text { The workers in the University use the equipment and devices and the } \\
\text { available technologies in a manner that enhance the competitive feature } \\
\text { to the University. }\end{array}$ & 3.944 & 0.802 & 5 & high \\
\hline 5. & $\begin{array}{l}\text { The University has organizational structure that clarifies the lines of } \\
\text { authority and he/she shall adhere to such thing. }\end{array}$ & 4.389 & 0.608 & 2 & high \\
\hline 6. & $\begin{array}{l}\text { The University shall evaluate periodically the effectiveness of the } \\
\text { internal control system }\end{array}$ & 3.833 & 0.786 & 7 & high \\
\hline 7. & The University shall evaluate periodically the operational efficiency & 3.556 & 0.922 & 10 & medium \\
\hline 8. & $\begin{array}{l}\text { The University has a clear plan to manage knowledge and considering it } \\
\text { as a strategic stockpile for learning. }\end{array}$ & 3.667 & 1.029 & 9 & high \\
\hline 9. & $\begin{array}{l}\text { The University has a clear plan for the optimal use of the available } \\
\text { economic resources. }\end{array}$ & 4.444 & 0.705 & 1 & high \\
\hline 10. & The University has high quality system for cost accounting. & 4.000 & 0.970 & 4 & high \\
\hline 11. & The University keep with the modern technological developments. & 3.778 & 0.808 & 8 & high \\
\hline 12. & $\begin{array}{l}\text { The workers in the University use the equipment and devices and the } \\
\text { available technology optimally. }\end{array}$ & 4.000 & 0.970 & 4 & high \\
\hline \multicolumn{2}{|c|}{ General Measure } & 3.986 & 0.536 & & high \\
\hline
\end{tabular}

We noticed from the abovementioned schedule that the relative importance to the general average (infrastructure to the facility and knowledge) is high, the general average reached to (3.986) and the standard deviation (0.536). The paragraph "the University has a clear plan to the best use of the available economic resources" took the first place, with the arithmetic average (4.444) and an increase relative importance while the paragraph "the University make a periodic evaluation for the operational competences" took the last place, with the arithmetic average (3.556) and a medium relative importance.

\subsubsection{The Relational Capital (Clients' Relations)}

Table 10. The arithmetic averages and standard deviations to the relational capital paragraphs

\begin{tabular}{|c|c|c|c|c|c|}
\hline No. & Paragraph & $\begin{array}{l}\text { The Arithmetic } \\
\text { Average }\end{array}$ & $\begin{array}{r}\text { Standard } \\
\text { deviation }\end{array}$ & Rank & $\begin{array}{l}\text { Relative } \\
\text { Importance }\end{array}$ \\
\hline 1. & The administration own a clear knowledge about the relational capital & 4.444 & 0.616 & 1 & high \\
\hline 2. & $\begin{array}{l}\text { The company has written trends about developing the relational } \\
\text { capital }\end{array}$ & 3.778 & 0.647 & 5 & high \\
\hline 3. & $\begin{array}{l}\text { There is a clear interest by the administration regarding their clients' } \\
\text { needs and interests }\end{array}$ & 4.389 & 0.698 & 2 & High \\
\hline 4. & $\begin{array}{l}\text { The administration respond to their clients' needs in order to develop } \\
\text { its services and products }\end{array}$ & 3.667 & 1.085 & 6 & High \\
\hline 5. & The administration seeks to reach to the client's satisfaction & 3.444 & 0.984 & 7 & Medium \\
\hline 6. & The administration seeks to build strong relations with their clients & 4.167 & 0.786 & 3 & High \\
\hline 7. & $\begin{array}{l}\text { The University asks its clients' about taking decisions related to its } \\
\text { products and services }\end{array}$ & 3.389 & 1.195 & 8 & Medium \\
\hline
\end{tabular}




\begin{tabular}{|c|c|c|c|c|c|}
\hline 8. & $\begin{array}{l}\text { The University make marketing researches to improve its market } \\
\text { share and open new majors. }\end{array}$ & 4.389 & 0.850 & 2 & High \\
\hline 9. & $\begin{array}{l}\text { The University make social activities in order to help the community } \\
\text { in the surrounding environment }\end{array}$ & 4.000 & & 4 & High \\
\hline 10. & $\begin{array}{l}\text { The University shall follow-up their students after graduation about } \\
\text { their acquiring of job opportunities as well as it provides them with } \\
\text { the appropriate training, if necessary. }\end{array}$ & 3.111 & 1.278 & 9 & Medium \\
\hline & The General Measure & 3.878 & 0.472 & & High \\
\hline
\end{tabular}

It has clearly been noticed from the abovementioned schedule the relative importance for the overall average to the relational capital paragraphs (customers' relations) are high since the overall average reached to (3.877) and the standard deviation reached to (0.472). The paragraph "the administration owns a clear knowledge about the relational capital concepts" took the first rank, with a standard deviation (4.444) and by a high relative importance, while the paragraph "the University follow-up its students after the graduation about their getting of work opportunities as well as it provides them with the sufficient training, if necessary" took the last rank, with a standard deviation (3.111) and by a medium relative importance.

In order to compare the dimensions of the intellectual capital for the rational administration the following schedule has been prepared:

Table 11. Overall averages and standard deviations to the intellectual capital dimensions of the rational administration

\begin{tabular}{llccc}
\hline No. & The dimension & $\begin{array}{c}\text { The overall } \\
\text { average }\end{array}$ & $\begin{array}{c}\text { The standard } \\
\text { deviation }\end{array}$ & $\begin{array}{c}\text { Rank } \\
\text { The relative } \\
\text { importance }\end{array}$ \\
\hline 1. The human capital (The human resources administration and the & 3.868 & 0.429 \\
\\
$\quad \begin{array}{l}\text { knowledge that such sources have). } \\
\text { 2. The structural capital (the infrastructure of the University and knowledge). }\end{array}$ & 3.986 & 3 \\
3. The relational capital (customers relations). & 3.878 & 0.536 \\
\hline The intellectual capital dimensions for the rational administration & 3.910 & 0.472 & 2 \\
\hline
\end{tabular}

The findings of the Table 11 indicate that the level of measuring of the intellectual capital dimensions to the rational administration regarding the level of relative importance is high. tha the overall average reached to (3.910) and the standard deviation (0.437), the schedule also showed that the structural capital (the infrastructure for the facility and knowledge) came in the first rank, and its overall average was (3.986) and the standard deviation (0.536), and by a high relative importance, while the human capital that includes (the human resources management and the knowledge that such resources have) came in the last rank by the average of (3.868) with (0.429) of a standard deviation with a high relative importance.

\subsection{The Multicollinearity Correlation Test}

Such phenomenon indicates that there is a written correlation almost completely between two or more variables, such thing magnifies the renewable variable $\mathrm{R} 2$ and makes its value more than its actual value. Thus, the factor value was calculated among the independent value according to the study sample, the results were as follows:

Table 12. The correlation matrix for the independent variables

\begin{tabular}{cccc}
\hline variable & The intellectual capital & The structural capital & The relational capital \\
\hline The human capital & 1.000 & & \\
The structural capital & $* * 0.710$ & 1.000 & 1.000 \\
The relational capital & $* * 0.708$ & $* * 0.813$ & \\
\hline
\end{tabular}

$(* *)$ indicates the indication level of 0.01 .

(Guajarati, 2004, p. 359) Table 12 indicates that the highest level of correlation among the two variables (the structural capital) and (the relational capital), reaches to (0.813), such thing denotes that multicollinearity exist between independent variables, the value of correlation factor that exceeds $(0.80)$ indicator denotes that multicollinearity problem does exist.

In order to assure that such sample is void of the multicollinearity problem, the variance inflation factor (VIF) is calculated to assure that there is no multicollinearity correlation among the independent variables, the results 
were as follows:

Table 13. The results of multicollinearity tests among the independent variables

\begin{tabular}{ccc}
\hline Variable & the variance inflation factor (VIF) & Tolerance \\
\hline The human capital & 2.243 & 0.449 \\
The structural capital & 3.295 & 0.303 \\
The relational capital & 3.277 & 0.305 \\
\hline
\end{tabular}

(Gujarati, 2004, p. 253) The table 13 indicates that variance inflation factor values were more than Number 1 and less than Number. 10 such thing assures that no multicollinearity existed among all the independent study variables

\subsection{Hypothesis Test}

we shall examine in such study portion the hypothesis test both the main hypothesis and its subgroup have been subjected to the analyzation of simple and multiple linear regression.

The main hypothesis $\mathrm{HO}$ :

No evidence of the statistical indication of the intellectual capital to the rational administration in achieving its quality of education.

The simple linear regression has used, in order to choose the hypotheses that are derived from the main one, the results were as follows:

H01: none evidence of the statistical indication to the human capital to the rational administration in achieving its quality of education.

Table 14. ** The findings of (human capital effect test) in achieving the excellence indicators to the University performance by applying the standards of quality assurance

\begin{tabular}{|c|c|c|c|c|c|c|c|c|c|c|}
\hline \multirow[t]{2}{*}{ The following variable } & \multicolumn{2}{|c|}{$\begin{array}{c}\text { Model } \\
\text { Summary }\end{array}$} & \multicolumn{3}{|c|}{$\begin{array}{c}\text { Variable Analyzing } \\
\text { Anova }\end{array}$} & \multicolumn{5}{|c|}{ Coefficients Table } \\
\hline & $\mathrm{R}$ & $\mathrm{R}^{2}$ & $\mathrm{~F}$ & $\mathrm{DF}$ & Sig F* & Statement & $\mathrm{B}$ & The standard mistake & $\mathrm{T}$ & Sigt* \\
\hline The intellectual capital (human) & & & & & & & & & & \\
\hline $\begin{array}{l}\text { For the rational University } \\
\text { administration in achieving its } \\
\text { quality of education }\end{array}$ & 0.639 & 0.408 & 11.020 & 1 & 0.004 & $\begin{array}{c}\text { The human } \\
\text { capital }\end{array}$ & 22.420 & 6.753 & 3.320 & 0.004 \\
\hline
\end{tabular}

The effect shall have a statistical indication when it reached level $((\alpha \leq 0.05)$.

The Table 14 findings indicate that the value of $(\mathrm{R}=0.639)$ such thing means that a positive relation between (achieving the excellence indicators for the University performance by applying the standards of quality assurance) and (human capital), it has been stated that determining factor $\left(R^{2}=0,408\right)$, such thing means that (the human capital) has explained around (49\%.8) of the variation in (achieving the indicators to the rational University administration in achieving its quality of education) while other variables remain fixed, $(F)$ value indicates that it reached (11.022) to the (sig=0.004) level, such thing confirms the declining significant at the level $(\mathrm{a} \leq 0.05)$ and in one degree of freedom.

It also has been indicated in the calculation' schedule that $(\mathrm{B}=19.763)$ and $(\mathrm{t}=3.947)$ at $(\mathrm{sig}=0.001)$ level, such thing confirms the variable significant at the level $(\mathrm{a} \leq 0.05)$.

Based on the foregoing, we shall both reject the first sub null hypothesis and accept the alternative sub hypothesis that indicates:

"There is a statistical indication evidence to the human capital of the rational administration in accomplishing its quality of education.

H02: There is no statistically significant effect of the structural capital of good governance in achieving quality of education 
Table 15. ** The findings of the (structural capital) effect in accomplishing the excellence indicators to the University performance by applying the standards of the quality assurance

\begin{tabular}{|c|c|c|c|c|c|c|c|c|c|c|}
\hline \multirow[t]{2}{*}{ The following variable } & \multicolumn{2}{|c|}{$\begin{array}{c}\text { Model } \\
\text { Summary }\end{array}$} & \multicolumn{3}{|c|}{$\begin{array}{c}\text { Variable Analyzing } \\
\text { Anova } \\
\end{array}$} & \multicolumn{5}{|c|}{ Coefficients Table } \\
\hline & $\mathrm{R}$ & $\mathrm{R}^{2}$ & $\mathrm{~F}$ & DF & $\operatorname{Sig} \mathrm{F}^{*}$ & Statement & $\mathrm{B}$ & The standard mistake & $\mathrm{T}$ & Sigt* \\
\hline $\begin{array}{l}\text { The intellectual capital } \\
\text { (structural) effect } \\
\text { For the rational University } \\
\text { administration in achieving } \\
\text { its quality of education }\end{array}$ & 0.702 & 0.493 & 15.582 & 1 & 0.001 & $\begin{array}{l}\text { The structural } \\
\text { capital }\end{array}$ & 19.763 & 5.007 & 3.947 & 0.001 \\
\hline
\end{tabular}

The statistical indication effect shall be at the level: $(\alpha \leq 0.05)$.

The results of Table 15 show that the value of $R=0.702$, which means that there is a positive relationship between achieving the indicators of excellence of university performance through the application of quality assurance standards and structural capital. The value of the coefficient of determination $\left(R^{2}=0.493\right)$, which means that (structural capital) has been explained by (49.3\%) of the variance in (achieving the indicators of good university management in achieving quality education), with the remaining factors constant. The value of (F) was 15.582 at the confidence level $(\mathrm{Sig}=0.001)$. This confirms the significance of the regression at $(\alpha \leq 0.05)$ and the degree of freedom. As shown in the table of transactions, the value of $(\mathrm{B}=19.763)$ and the value of $(\mathrm{t}=$ $3.947)$ at the level of confidence ( $\mathrm{Sig}=0.001)$ and these confirm the significance of the coefficient at the level $(\alpha$ $\leq 0.05)$. Based on the above, we reject the second nihilistic hypothesis and accept the alternative sub-hypothesis which states:

"There is a statistically significant impact of the structural capital of good governance in achieving quality education

H03: There is no statistically significant effect of relational capital to good governance in achieving quality education.

Table 16. * Results of the impact test (relational capital) in good governance in achieving the quality of education in them

\begin{tabular}{|c|c|c|c|c|c|c|c|c|c|c|}
\hline \multirow[t]{2}{*}{ The following variable } & \multicolumn{2}{|c|}{$\begin{array}{c}\text { Model } \\
\text { Summary }\end{array}$} & \multicolumn{3}{|c|}{$\begin{array}{c}\text { Variable Analyzing } \\
\text { Anova }\end{array}$} & \multicolumn{5}{|c|}{ Coefficients Table } \\
\hline & $\mathrm{R}$ & $\mathrm{R}^{2}$ & $\mathrm{~F}$ & DF & Sig F* & Statement & $\mathrm{B}$ & The standard mistake & $\mathrm{T}$ & Sigt* \\
\hline $\begin{array}{l}\text { The intellectual capital } \\
\text { (relational) effect } \\
\text { For the rational University } \\
\text { administration in achieving its } \\
\text { quality of education }\end{array}$ & 0.662 & 0.438 & 12.477 & 1 & 0.003 & $\begin{array}{l}\text { The relational } \\
\text { capital }\end{array}$ & 21.126 & 5.981 & 3.532 & 0.003 \\
\hline
\end{tabular}

* The effect is statistically significant at $(\alpha \leq 0.05)$.

The results of Table 16 indicate that the value of $R=0.662$ means that there is a positive relationship between achieving the indicators of excellence of the university performance through the application of quality assurance standards and the relational capital, It is clear that the value of the coefficient of determination $\left(\mathrm{R}^{2}=0.438\right)$, which means that (relational capital) explained $43.8 \%$ of the variance in the achievement of indicators of good university management in achieving the quality of education. The value of $(F)$ has reached (12.477) at the level of confidence ( $\mathrm{Sig}=0.003)$ and this confirms the significance of the regression at the level $(\alpha \leq 0.05)$ and the degree of freedom of one. As shown in the table of transactions, the value of $(B=21.126)$ and the value of $(t=$ $3.532)$ at the level of confidence ( $\mathrm{Sig}=0.003)$ and these confirm the significance of the coefficient at the level $(\alpha$ $\leq 0.05$ ).

Based on the foregoing, we shall both reject the third sub null hypothesis and accept the alternative sub hypothesis that indicates:

"There is a statistical indication evidence to the relational capital in achieving the excellence indicators to the University performance by applying the standards of the quality of education.

Multiple linear regression has been used to test the main hypothesis, the findings were as follows: 
Table 17. **the findings of the (intellectual capital) effect to the rational administration in achieving its quality of education

\begin{tabular}{|c|c|c|c|c|c|c|c|c|c|c|}
\hline \multirow[t]{2}{*}{ The following variable } & \multicolumn{2}{|c|}{$\begin{array}{c}\text { Model } \\
\text { Summary }\end{array}$} & \multicolumn{3}{|c|}{$\begin{array}{c}\text { Variable Analyzing } \\
\text { Anova }\end{array}$} & \multicolumn{5}{|c|}{ Coefficients Table } \\
\hline & $\mathrm{R}$ & $\mathrm{R}^{2}$ & $\mathrm{~F}$ & $\mathrm{DF}$ & Sig F* & Statement & $\mathrm{B}$ & The standard mistake & $\mathrm{T}$ & Sigt* \\
\hline \multirow{3}{*}{$\begin{array}{l}\text { Achieving indicators to the } \\
\text { rational University } \\
\text { administration in achieving } \\
\text { its quality of education }\end{array}$} & \multirow{3}{*}{0.737} & \multirow{3}{*}{0.543} & \multirow{3}{*}{5.536} & \multirow{3}{*}{3} & \multirow{3}{*}{0.010} & The Human capital & 8.271 & 9.502 & 3.780 & 0.039 \\
\hline & & & & & & The intellectual capital & 11.002 & 9.231 & 9.912 & 0.025 \\
\hline & & & & & & The relational capital & 5.663 & 10.443 & 2.624 & 0.059 \\
\hline
\end{tabular}

* The effect is statistically significant at $(\alpha \leq 0.05)$.

The results of the table indicate that the correlation coefficient $(\mathrm{R}=0.737)$ refers to the relationship between the independent variables and the dependent variable. The effect of the independent variables (the intellectual capital of good governance) on the dependent variable (achievement of indicators of good university administration in achieving the quality of education) The mean value of the calculated factor $(\mathrm{R} 2=0.543)$ was $54.3 \%$ of the difference in the achievement of indicators Excellence for university performance through the application of quality assurance standards (can be explained by the variance in the (intellectual capital of good governance) Combined.

The table of coefficients showed that the value of B at (human capital) reached (8.271) and the value of $t$ (3.780) and the level of significance ( $\mathrm{Sig}=0.039$ ), indicating that the effect of this dimension is significant. B (structural capital) showed a value of (11.002) and a t value of (3.912) and a level of significance (Sig = 0.025), indicating that the effect of this dimension is significant. The value of B at ( relational capital) was (5.663) and t (2.624) and the level of significance ( $\mathrm{Sig}=0.059$ ), indicating that the effect of this dimension was significant.

Based on the above, we reject the main premise and accept the alternative hypothesis which states:

"There is a significant impact of the intellectual capital of good governance in achieving the quality of education in it.

\section{The Findings}

1) The faculty members bear the burden and the responsibility of both achieving and insuring the total quality in the Universities. Thus, they own the key whether of success or failure in achieving the quality according to their intellectual capital in addition to their culture, motivation, preparation, and their total believe about what they are doing.

2) The faculty members play a vital role in achieving the quality to their Universities because of their intellectual capital. In fact, such quality achievement in education constitutes a challenge for the higher education officials, and its impact on the faculty members is in line with their understanding and keeping acquired quality in mind, because they are considered as effective factors in developing the performance in their universities, and by that naturally helps them in reaching what is more than their traditional and intellectual factors and their work tasks, they are expected to contribute in program management and strategic planning, achieve the quality, provide income resources to the Universities in which they work in research and consultancies.

3) Considering the knowledge explosion and communication techniques development as well as the appearance of globalization phenomenon and the orientation towards the educational reform, the development of studies researches in the University field, it becomes necessary to prepare faculty members that are intellectually capable to adapt on such challenges and changes. Especially, the Universities' administrations realized that the effectiveness of the faculty members' performance is not confined only to the academic staff but also to the whole Universities' reputation. Moreover, the faculty members strongly believe that the University's fame are derived from their high level and performance in teaching and scientific research fields, because the evaluation of faculty members in most Universities concentrates on three main fields, such as teaching, the intellectual scientific producing, the performance in other activities inside and outside the University.

4) The vocational development to the faculty members has not been indicated as a purpose, but rather as a mean for adjusting ideas, developing learning and education until achieving the total quality.

5) There is a statistical evidence to the intellectual capital components to the rational administration for the private and governmental Universities in achieving its quality of education. 


\section{Recommendations}

1) The quality assurance standards shall be developed to the faculty members, at the intellectual level and taking advantages of the academic accreditation institutions' experiences, the Universities, faculties, and colleges that have tangible experiences in such thing whether at the local or global levels.

2) The establishment of a system for the intellectual, scientific and professional growth of faculty members in higher education is mandatory, accompanied by a range of appropriate incentives, and avoids the obstacles of professional scientific development. and relevant planning and development systems of the ministries and institutions of higher education may undertake this task, and the system will be subject to local or international accreditation procedures.

3) The centers of intellectual and professional development should be established for the members of the faculty to ensure its quality in institutions of higher education. It is necessary to involve them in the development courses as an item of the promotion ladder in universities. In addition to the need to disseminate the culture of quality and professional development

4) The Universities have both to determine its intellectual capital and to identify the scientific means to maintain and improve it, in order to guarantee its quality of education.

\section{References}

Al Garaawi, M. I. H. (2016). The extent of the application of the principles of total quality management in higher education: A comparative study between the government colleges and community colleges from the viewpoint of a sample of lecturers. AL-Qadisiyah Journal for Administrative and Economic Sciences, 18(1).

Al Hussaine, S. H. (2009). Administrative Leadership and its Impact on Human Resource Management Strategic: A Field Study in Governmental Organizations in Nasiriyah Governorate, Iraq. Unpublished Master Thesis, The Arabic Academy in Denmark, p. 34.

Alawamrah, A. A. (2016). Influential Relationship between Intellectual Capital and The Development of Creative Abilities of The Faculty Members in The Faculty of Educational Sciences - University of Jordan. Arab Journal for Quality Assurance in Higher Education, 9(23), 53-75. https://doi.org/10.20428/AJQAHE.9.1.3

Al-Hawary, S. I. S., \& Nusair, W. K. I. (2017). Impact of Human Resource Strategies on Perceived Organizational Support at Jordanian Public Universities. Global Journal of Management and Business Research, 17(No. 1).

Alserhan, H. F. (2017). The Role of Intellectual Capital in Achieving a Competitive Advantage: A Field Study on Jordanian Private Universities in the Northern Region. Global Journal of Management and Business Research, 17(5). https://doi.org/10.6007/IJAREMS/v6-i2/3139

Alzoubaidi, G. D. T., Mahmoud, A. A., \& Hussein, W. (2017). Analyzing the dimensions of the intellectual capital in the educational institution by using SWOT technique. Journal of University of Babylon, Applied Sciences, 25(1).

Alzyadat, A. (2015). The Effect of Intellectual Capital Components on the Financial Performance of Jordanian Islamic Banks. Unpublished Doctoral Thesis, International Islamic University, Amman, Jordan.

Barbosa, S., Vale, J., Teixeira, V. V., \& Castelo, B. M. (2016). Intellectual Capital and Performance in Higher Education Organizations. Paper presented at the the International Conference Theory and Applications in the Knowledge Economy, Aveiro, Portugal.

Cañibano, M. L., \& Sanchez, P. (2008). Intellectual Capital Management and Reporting in Universities and Research Institutions. Estudios de Economía Aplicada, 26(2), 7-26.

Cricelli, L., Greco, M., Grimaldi, M., \& Dueñas, L. P. L. (2018). Intellectual capital and university performance in emerging countries: Evidence from Colombian public universities. Journal of Intellectual Capital, 19(1), 71-95. https://doi.org/10.1108/JIC-02-2017-0037

Dahlman, C. J. (2002). Knowledge for Development: Assessment Framework and Benchmarking. Singapore: OECD.

Federation of the Universities of the Islamic World. (2010). Strategy for the Development of University Education in the Islamic World. Retrieved from http://www.isesco.org.ma

Hadad, S. (2017). Knowledge Economy: Characteristics and Dimensions. Management Dynamics in the 
Knowledge Economy, 5(2), 203-225. https://doi.org/10.25019/MDKE/5.2.03

Hassan, R. (2010). Strategic Approach to Planning and Development of Human Resources. El Dar El Gamaya, Egypt.

Kannan, G., \& Aulbur, A. G. (2004). Intellectual capital: Measurement effectiveness. Journal of Intellectual Capital, 5(3), 389-413. https://doi.org/10.1108/14691930410550363

Marr, B., Gray, D., \& Neely, A. (2003). Why do firms measure their intellectual capital. Journal of Intellectual Capital, 4(4), 441-464. https://doi.org/10.1108/14691930310504509

Ognjanović, J. (2016). Ntellectual Capital: Characteristics And Significance in the Service Sector. Економика, 62(3), 159-172.

Omar, A. M., \& Hamdi, M. (2001). Methods and models of measuring intellectual capital. Introduction to the 5th International Forum on Intellectual Capital in Arab Business Organizations under the Modern Economies, within the framework of the No. 05: Approaches and Methods of Measuring Intellectual Capital in Business Organizations, 13-14 December 2011, p. 4.

Ramírez, Y., Tejada, Á., \& Gordillo, S. (2013). Recognition of intellectual capital importance in the university sector. International Journal of Business and Social Research, 3(4), 27-41.

Ramona, T., \& Anca, Ș. (2015). The Assesment of Intellectual Capital In Romanian Universities. Studies in Business and Economics, 10(3), 100-110. https://doi.org/10.1515/sbe-2015-0040

Rezende, J. F. D. C., Silva, C. M. M. D., Ferreira, D., Neto, S. C., \& Andrade, R. O. B. D. (2017). The Intellectual Capital and the value creation on the Brazilian Higher Education Institutions: Perspectives of the coordinators of undergraduate Business Administration Courses. International Journal of Business Management and Economic Research (IJBMER), 8(1), 849-861.

Ricceri, F. (2008). Intellectual capital and knowledge management: Strategic management of knowledge resources. London: Routladge.

Rizvi, F. (2005). International Education and the Production of Cosmopolitan Identities: Transnational Seminar Series.

Secundo, G., Perez, S., Martinaitis, Ž., \& Heinz, L. K. (2017). An Intellectual Capital framework to measure universities' third mission activities. Technological Forecasting and Social Change, 123, 229-239. https://doi.org/10.1016/j.techfore.2016.12.013

Todericiu, R., \& Stanit, A. (2016). Universities Intellectual Capital. Revista Academiei Fortelor Terestre, 21(4), 348-356.

\section{Copyrights}

Copyright for this article is retained by the author(s), with first publication rights granted to the journal.

This is an open-access article distributed under the terms and conditions of the Creative Commons Attribution license (http://creativecommons.org/licenses/by/4.0/). 